\title{
Testing for contagion from oil and developed markets to emerging markets: An empirical analysis using systemic risk parameter
}

\author{
Edgardo Cayón \\ CESA Business School, \\ Colombia \\ ecayon@,cesa.edu.co
}

\author{
Julio Sarmiento \\ Pontificia Universidad Javeriana, \\ Colombia \\ sarmien@javeriana.edu.co
}

\begin{abstract}
This paper analyses the volatility transmission from changes in prices in oil and developed stock markets to emerging markets. We test for volatility contagion from these two factors while allowing for interaction between them in order to account for diversification effects using the M-GARCH framework in a traditional two-factor market model. We find evidence that for all the periods under observation the covariance between developed markets and oil prices is negative. This negative covariance leads to a diversification effect, which lowers the impact of developed market prices on the systemic risk of emerging markets and gives support for the decoupling hypothesis concerning emerging market volatility during the beginning of the global financial crisis (GFC).
\end{abstract}

Received:

May, 2019

1st Revision:

December, 2019

Accepted:

May, 2020

DOI:

$10.14254 / 2071$ $8330.2020 / 13-2 / 7$

Keywords: oil, contagion, emerging markets, systemic risk.

JEL Classification: G1, G15, G17

\section{INTRODUCTION}

The relationship between oil prices and stock markets has been a subject of research in finance and economics. A series of stylized facts have been observed, of special interest is the fact that the relationship between oil prices and stock markets is an inverse one, but recently there emerged also evidence that in the case of emerging markets stock prices the relation is a positive one (Syed A Basher \& Sadorsky, 2006). For example, Raza et al. (2016) found evidence that positive shocks in oil prices had a positive impact on large emerging markets stock indices. In a study by Kayalar, Küçüközmen, and Selcuk-Kestel (2017), the authors categorized the data into oil exporters/importers and developed/emerging markets economies, and their results showed that the relationship between oil and stock prices was stronger in those countries categorized 
as both oil exporters and emerging markets. There is also evidence that emerging stock prices and oil prices exhibit a "positive leverage effect" which means that positive increases in oil and emerging stock prices have a larger magnitude in terms of variance than negative ones (Syed Abul Basher \& Sadorsky, 2016).

In this paper we model the volatility transmission between the price of oil and stocks in emerging markets in the context of financial contagion in order to test the validity of the previous findings in the context of financial contagion. The paper is organized as follows: Section 2 presents literature review on the subject, section 3 describes the methodology and our choice of variables for a dynamic conditional covariance model as well as our multivariate general autoregressive conditional heteroskedasticity model (M-GARCH) in a two-factor model framework in a financial contagion context. Section 4 contains the summary of our results as well as our robustness test, and finally section 5 concludes.

\section{LITERATURE REVIEW}

In the case of developed economies, there are mixed results regarding the dependence structure of oil and stock markets. For instance, a study by Mensi et al. (2017) found that there is a tail dependence between oil markets and major world stock indices. Another study by Ding, Kim, and Park (2016) found that although there is casual relationship between some Asian markets and Dubai oil prices, there was no causality between Dubai oil prices and Chinese stock markets which is the second oil consumer of the world. In the case of Europe, there was evidence of a clear volatility spillover between shocks in oil prices and the European global index, even after controlling by economic sectors (Arouri, Jouini \& Nguyen, 2012). There is also a segmentation effect for the type of shock event that affects the market, for example demand-oil shocks can affect some producing countries and supply-oil can have no effect whatsoever in the same oil producing countries (Syed Abul Basher, Haug, \& Sadorsky, 2018). Oil prices tend to respond differently to surprises in political and economic news that have implications for the supply and demand of oil, usually announcements related to changes in the demand of oil are the ones that have the highest impact (Byrne, Lorusso \& Xu, 2018).

Most of the studies that analyze the relationship between stock markets and oil are in the context of financial contagion. For example, Fang and Egan (2018) used a time varying cut-off model to measure the relationship between the excess returns of oil and excess returns from the Chinese stock market. They found evidence of financial contagion between these two markets and that in times of turbulence the positive correlation between oil and the Chinese stock market weakens diversification. Zhang and Liu (2018) modeled the propagation of financial contagion from oil shocks among a sample of seven countries that included developed and emerging markets. The authors found that in the case of Brazil financial contagion to the local stock market occurred in the form of contemporaneous shocks from both the developed countries stock markets and oil. Hassan, Hoque, and Gasbarro (2019) used a dynamic conditional correlation model to test for evidence of cross market linkages among oil and Brazil, Russia, India and China which are commonly referred as the BRIC countries. However, the authors focused on the stocks from these countries that are relevant to Islamic investors ${ }^{1}$ and then compared the effect of contagion of these stocks to oil. The authors found that this type of stocks were less vulnerable to oil contagion than the conventional indices from the BRIC countries that included all type of stocks. Finally, it is important to mention that all of the previous studies found that at the time of the global financial crisis (GFC) in 2008 there was evidence of financial contagion between oil and all the above-mentioned stock markets. In the

\footnotetext{
1 The authors used stocks from BRIC countries that are not contrarian to Sharia law, that means that stocks that derive more than $5 \%$ of their revenue from alcohol, tobacco, pork related products, conventional financial services, defense/weapons, gambling or adult entertainment are excluded from the calculations.
} 
case of financial contagion and energy markets, Wen, Wei and Huang (2012) used a time-varying approach found increase interdependence between crude oil prices and stocks during the GFC, using a different approach with regime switching models Guo, Chen and Huang (2011) reached the same conclusion of increased interdependence between stock markets and crude oil prices in the GFC.

Our study finds that systemic shocks emanating from changes in the price of oil and developed markets tend to fit within the "coupling-decoupling" hypothesis (Dooley \& Hutchison, 2009). The couplingdecoupling hypothesis states that in recent years the linkages between developed and emerging markets events tend to be non-synchronous especially at the beginning of global crisis like the GFC and the European Sovereign Debt (ESD) crisis; this is the "decoupling" part of the hypothesis. The "coupling" part of the hypothesis occurs after the initial shock impacts the real economy and then affects emerging markets as a lagged effect. This is why in our study we use a dynamic conditional covariance in a two-factor framework to allow for innovation between the factors (oil and developed market) and their effect in the systemic variance of emerging markets.

\section{DATA AND METHODOLOGY}

The data for the present study was retrieved from Bloomberg. Our sample contains the daily closing price of the West Texas Intermediate Index (WTI) which is our proxy for oil crude prices. The MSCI Emerging market index which represent the large and mid-capitalization enterprises from 23 emerging countries as well as its counterpart the MSCI world index which represent the large and mid-capitalization enterprises from 23 developed markets. The data comprehends the period between January 3 2005-June 10 2019. Summary statistics for the returns are presented in Table 1.

Table 1

Descriptive statistics for the WTI, MSCI emerging market index and de MSCI world market index

\begin{tabular}{|l|c|c|c|}
\hline & $\begin{array}{c}\text { WTI- West Texas } \\
\text { Intermediate }\end{array}$ & $\begin{array}{c}\text { MSCI Emerging Market } \\
\text { Index }\end{array}$ & MSCI World Index \\
\hline Mean & 0.0001 & 0.0002 & 0.0002 \\
\hline Median & 0.0008 & 0.0009 & 0.0007 \\
\hline Maximum & 0.2128 & 0.1007 & 0.0910 \\
\hline Minimum & -0.1307 & -0.0999 & -0.0733 \\
\hline Std. Dev. & 0.0236 & 0.0125 & 0.0101 \\
\hline Skewness & 0.1911 & -0.5571 & -0.5302 \\
\hline Kurtosis & 8.2824 & 11.9159 & 12.7396 \\
\hline Observations & 3,627 & 3,627 & 3,627 \\
\hline
\end{tabular}

Note: Descriptive statistics for the three indices from January 3, 2005 to June 10, 2019

We can observe that in the case of oil the data is positively skewed with a high kurtosis while the stock indices exhibit negative skewness with high kurtosis. This fact is important for our choice of model for estimating conditional returns. We use daily returns of oil and the MSCI World Index as common factors of shock transmission to the MSCI Emerging Market index. In order the effectively measure the effects of shocks in oil prices on the MSCI we divided the sample into a series of bullish and bearish sub periods in our sample. As observed from Figure 1, the first bullish period for oil prices (UBP) goes from January 3, 2005 to July 3, 2008. 


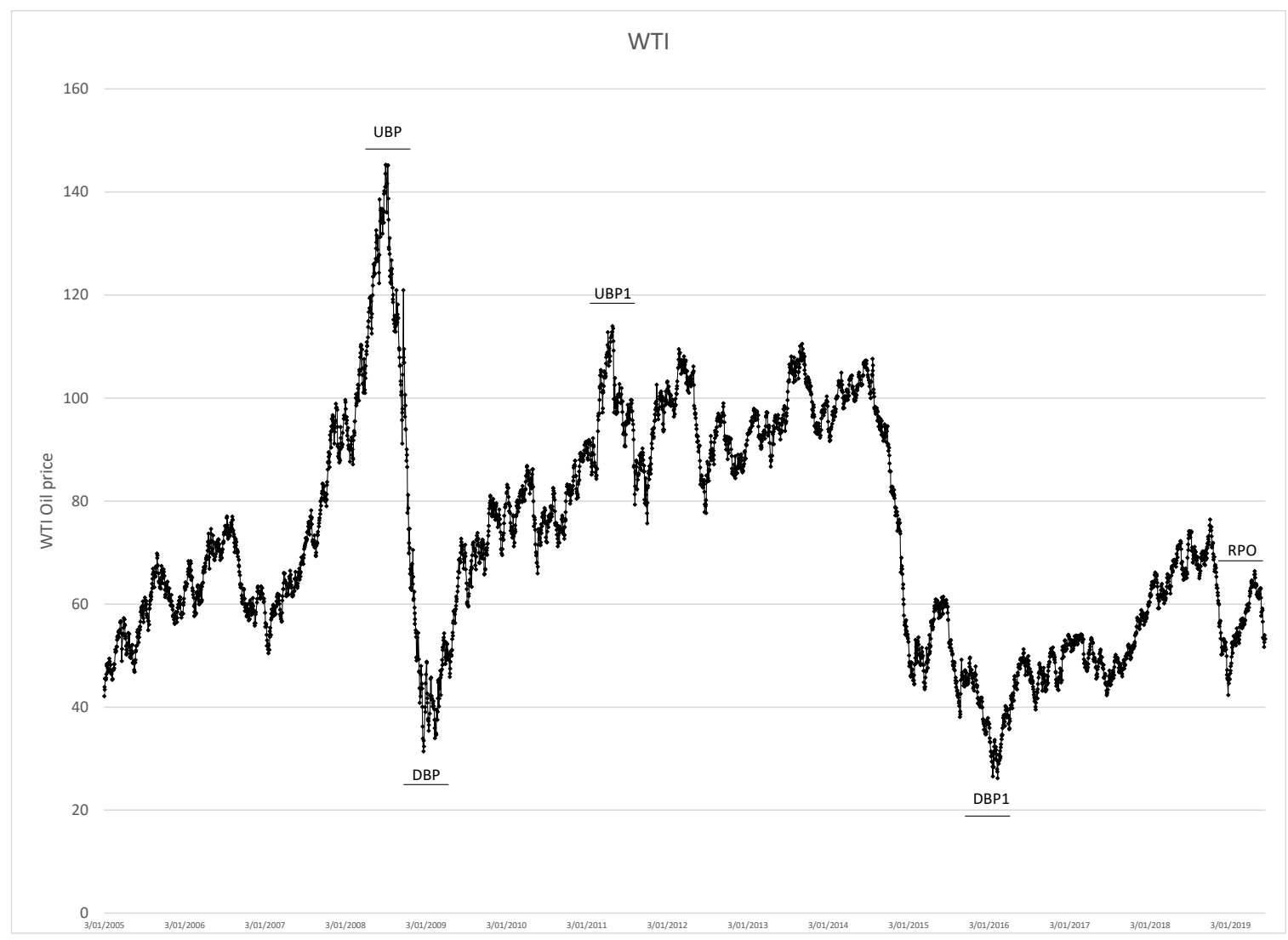

Figure 1. Oil prices bullish and bearish periods from January 3, 2005 to June 10, 2019

Note: In order to identify the bullish and bearish periods we use the major differences between maximum and minimum prices within the total observation period.

Conversely, the first bearish period (DBP) for oil prices goes from July 7, 2008 to December 22, 2008. The second bullish period (UBP1) is dated from December 23, 2008 to April 29, 2011 and the second bearish period (DBP1) is dated from May 2, 2011 to February 11, 2016. The last part of the sample is deemed as a recovery oil price period (RPO) since it is too short of a window to identify a trend. In graph 2, we can observe the bullish and bearish periods for the MSCI World Index:

The first bullish period for developed stock market prices (DUBV) goes from January 3, 2005 to October 31, 2007. The first bearish period (DDBPV) for developed stock market prices goes from November 1, 2007 to March 9, 2009. The second bullish period (DUBV1) goes from March 10, 2009 to January 26, 2015. The last part of the sample is a recovery developed stock market period (RPV) since it is too short of a window to identify a trend. In the present study, contagion is defined as a significant change in the comovements of returns across markets, conditional on a shock in one market or a group of markets. In the present study, we use the dynamics of returns between oil prices and the MSCI world index in order to explore if there is evidence of contagion effects from these two sources of volatility to the MSCI Emerging market index. We hypothesize that since emerging countries' economies are highly dependent on commodity prices and other exports of goods to developed countries a significant portion of the variance in the MSCI emerging market index should be explained by the volatility of oil prices (WTI) and volatility in the economic conditions of developed economies (MSCI World Index). 


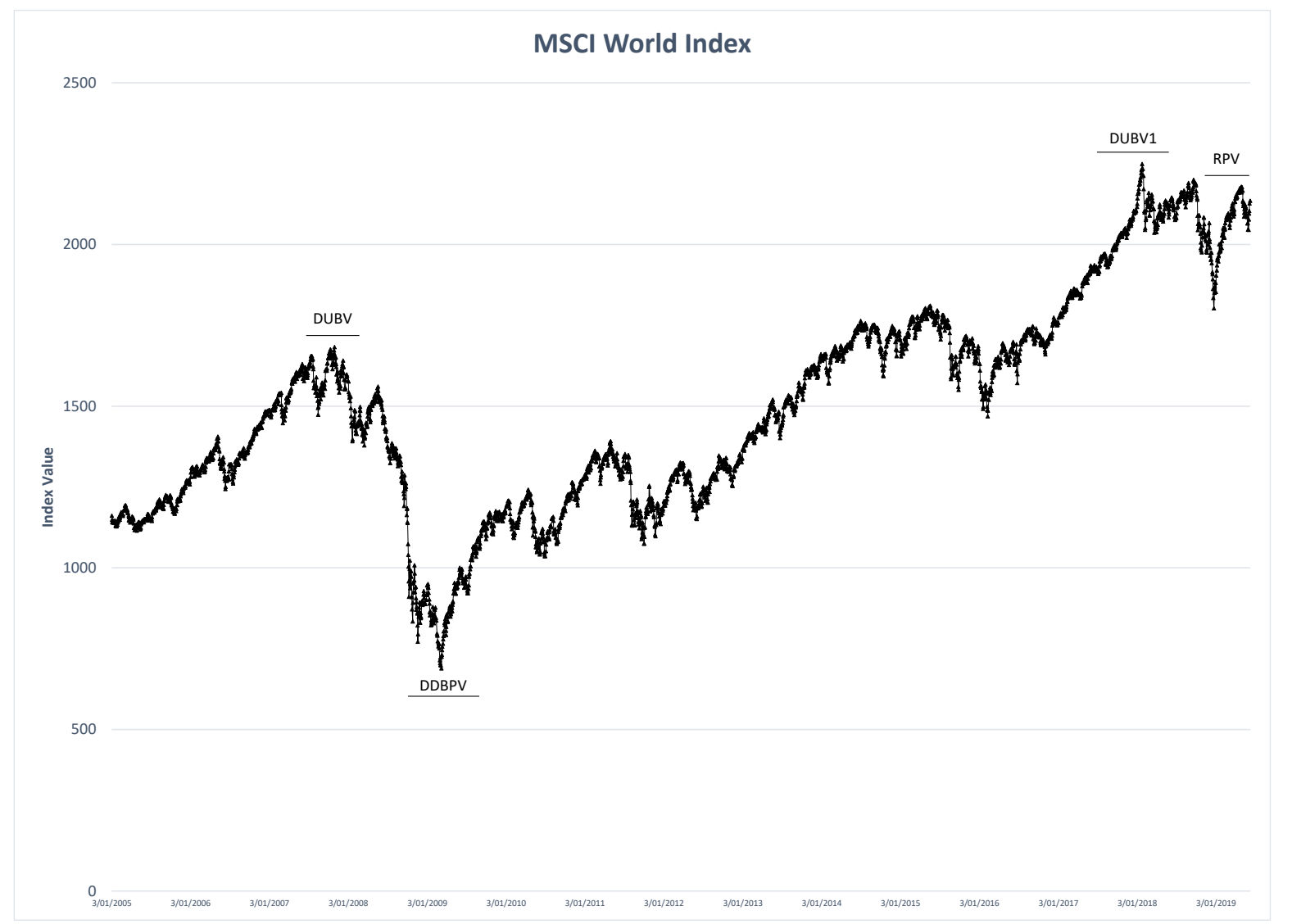

Figure 2. MSCI World Index bullish and bearish periods from January 3, 2005 to June 10, 2019 Note: In order to identify the bullish and bearish periods we use the major differences between maximum and minimum prices within the total observation period.

We evaluate evidence for contagion in the time-varying volatility of the MSCI emerging market index return across different bullish and bearish periods of oil prices and the MSCI world index as mentioned in the previous section. We follow the same procedure as Cayon and Thorp (2014) for modelling systematic shocks in financial crisis. The first step is to allow the conditional means of oil prices and the MSCI world index to follow an ARMA process in the following forms (see equation 1) in order to ensure that the residuals employed in the calculation of the multivariate garch model (M-GARCH) really capture the idiosyncratic risk of each variable under scrutiny. Therefore, the proposed ARMA process are:

$$
\begin{aligned}
& r_{\text {emer }, t}=\rho_{0}+\rho_{1, \text { emer }} r_{\text {devel }, t-1}+\rho_{2, \text { emer }} r_{\text {oil }, t-1}+\rho_{3, \text { emer }} r_{\text {emer }, t-1}+\theta_{4, \text { emer }} \varepsilon_{\text {emer }, t-1}+\varepsilon_{\text {emer }, t} \\
& r_{\text {oil }, t}=\rho_{0}+\rho_{1, \text { oil }} r_{\text {devel }, t}+\rho_{2, \text { oil }} r_{\text {oil }, t-1}+\theta_{3, \text { oil }} \varepsilon_{\text {oil }, t-1}+\varepsilon_{\text {oil }, t} \\
& r_{\text {devel }, t}=\rho_{0}+\rho_{1, \text { devel }} r_{\text {oil }, t}+\rho_{2, \text { devel }} r_{\text {devel }, t-1}+\theta_{3, \text { devel }} \varepsilon_{\text {devel }, t-1}+\varepsilon_{\text {devel }, t}
\end{aligned}
$$

Where the $r_{\text {emer,t }}$ are the daily returns of the MSCI emerging market index, $r_{\text {oil }, t}$ are the daily returns of WTI index, and $r_{\text {devel, },}$ are the daily returns of the MSCI world index, in each ARMA process of $r_{\text {oil }, t}$ and $r_{\text {devel, } t}$ we account for the contemporaneous interaction between each contagion factor. In the case of the MSCI emerging market index ARMA model, we allow for autoregressive interaction for both contagion factors $\left(r_{\text {devel }, t-1}\right.$ and $\left.r_{\text {oil }, t-1}\right)$. The next step is to account for the changes in conditional covariance that 
originate from equation (1). This is done by modelling the covariance between the MSCI emerging market index, MSCI world index and the price of oil using the following M-GARCH model in equation (2):

$$
\begin{aligned}
& h_{\text {emer }}=\alpha_{0}+\alpha_{1, \text { emer }_{t}} \varepsilon_{\text {emer }}^{2}+\alpha_{2, \text { emer }_{t}} h_{\text {emer } r_{-1}} \\
& h_{o i l_{t}}=\alpha_{0}+\alpha_{1, o i l_{t}} \varepsilon_{o i l_{t-1}}^{2}+\alpha_{2, o i l_{t}} h_{o i l_{t-1}} \\
& h_{\text {devel }_{t}}=\alpha_{0}+\alpha_{1, \text { devel }} \varepsilon_{\text {devel }_{t_{-1}}}^{2}+\alpha_{2, \text { devel }} h_{\text {devel }_{-1}}
\end{aligned}
$$

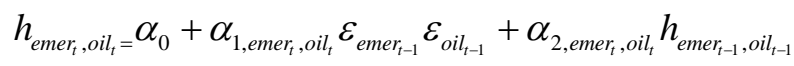

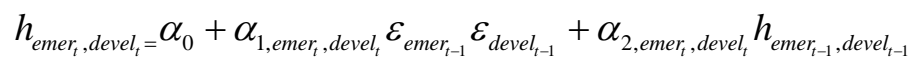

$$
\begin{aligned}
& h_{\text {oil }, \text { devel }}=\alpha_{0}+\alpha_{1, \text { oil } l_{t} \text {,evel }} \varepsilon_{\text {oil }} \varepsilon_{t-1} \varepsilon_{\text {deve } l_{t-1}}+\alpha_{2, \text { oil }_{t} \text {,devel }} h_{\text {oil }_{t-1} \text {,deve } l_{t-1}}
\end{aligned}
$$

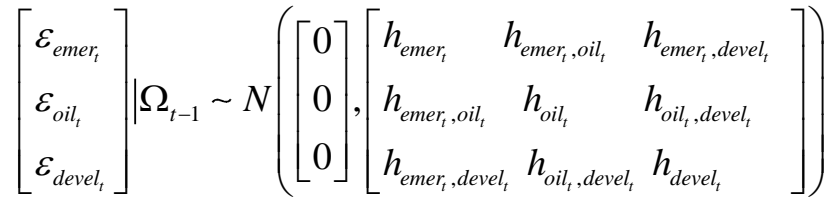

Where $h_{\text {emer }}$ is the conditional variance of filtered returns of the MSCI emerging market index, $h_{o i l_{t}}$ is the conditional variance of filtered returns of the WTI index, and $h_{\text {devel }}$ is the conditional variance of filtered returns of the MSCI world index. $h_{\text {emer, }, \text { oil }}$ is the covariance between the MSCI emerging market index and the WTI index, $h_{\text {emer, }, \text { devel }}$ is the covariance between the MSCI emerging market index and the MSCI world index, and finally $h_{\text {oil } l_{\text {,devel }}}$ is the covariance between the WTI index and MSCI world index. In order to avoid negative volatilities we used a diagonal BEKK specification. Using the fitted values from the MGARCH, we can compute the $\beta$ of a two factor model as:

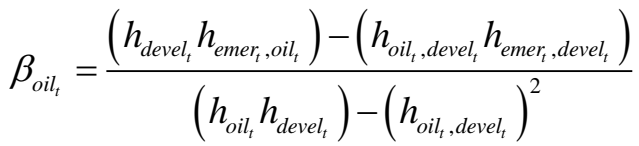

$$
\begin{aligned}
& \beta_{\text {devel }_{t}}=\frac{\left(h_{\text {oil }_{t}} h_{\text {emer }_{t} \text {,evel }}\right)-\left(h_{\text {oil }_{t} \text {,evel }} h_{\text {emer }_{t}, \text { oil }_{t}}\right)}{\left(h_{\text {ol }_{t}} h_{\text {devel }_{t}}\right)-\left(h_{\text {oil }_{t} \text {,devel }}\right)^{2}}
\end{aligned}
$$

The advantage of this specification is that we can discompose the variance of the MSCI emerging market index two factor model into systematic and idiosyncratic components in the following form:

$$
h_{\text {emer }}=\beta_{\text {oil }}{ }^{2} h_{\text {oil }}+\beta_{\text {devel }}{ }^{2} h_{\text {devel }}+2 \beta_{\text {oil }} \beta_{\text {devel }} h_{\text {oil }} \text {, devel } l_{t}+h_{\varepsilon_{t}}
$$

where $h_{e m e r_{t}}$ is the variance of the MSCI emerging market index, $\beta_{o i l_{t}}{ }^{2} h_{o i l_{t}}$ is the part of the variance attributed the systematic shocks transmitted by WTI index, and $\beta_{\text {devel }}{ }^{2} h_{\text {devel }}$ is the part of the variance attributed to the systematic shocks transmitted by the MSCI world index. The term $2 \beta_{\text {oil }} \beta_{\text {devel }_{t}} h_{\text {oil }}$,devel $l_{t}$ accounts for the effect of the covariance between the two systematic factors on the variance of the MSCI emerging market index, and $h_{\varepsilon_{t}}$ is the part of the variance attributed to idiosyncratic factors. Therefore, we can discompose the variance of the MSCI emerging market index as a proportion of systematic and idiosyncratic risk in the form of equation (5): 


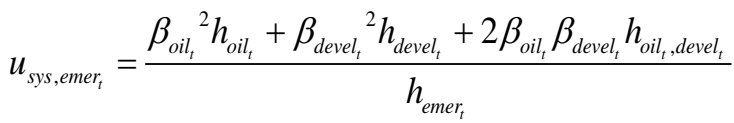

$$
\begin{aligned}
& u_{\text {idio, emer }}=\frac{h_{\varepsilon_{t}}}{h_{\text {emer }}}
\end{aligned}
$$

Once we have the series of the proportion of idiosyncratic risk form equation (5) we can proceed to the evaluation of contagion from oil shocks and developed markets by using equation (6):

$$
\begin{aligned}
& u_{s y s, \text { eme } r_{t}}=\varphi_{0}+\varphi_{1} u_{s y s, e m e r_{t-1}}+\varphi_{2} U P B+\varphi_{3} D P B+\varphi_{4} U P B 1+\varphi_{5} D P B 1 \\
& u_{s y s, e m e r_{t}}=\varphi_{0}+\varphi_{1} u_{s y s, e m e r_{t-1}}+\varphi_{2} D U B V+\varphi_{3} D D B P V+\varphi_{4} D U B V 1
\end{aligned}
$$

In equation (6) we are testing for breaks in the proportion of idiosyncratic risk due to the systematic shocks originated form the interaction between the WTI and MSCI world index. In this specification UPB, DPB, UPB1, DPB1, DUBV, DDBPV, and DUBV1 all take the value of one or zero otherwise in the periods described in section 2. Therefore, contagion in the form of changes in correlation is detected when any of the indicator $(\varphi)$ coefficients are statistically significant.

\section{EMPIRICAL RESULTS AND DISCUSSION}

The results obtained from equation (6) are summarized in Table 2, when we analyze the effects of oil shocks in the systemic risk of the MSCI emerging market index, we observe that all the indicator $(\varphi)$ coefficients are statistically significant with the exception of the last bearish period (DBP2) is dated from May 2, 2011 to February 11, 2016. In the case of developed markets all of the indicator $(\varphi)$ coefficients are also statistically significant with the exception of the first bearish period (DDBPV) for developed stock market prices dated from November 1, 2007 to March 9, 2009.

Table 2

\begin{tabular}{|c|c|c|c|}
\hline \multicolumn{2}{|c|}{ Dependent variable $\left(u_{\text {sys }, e m e r_{t}}\right)$} & & \multirow[b]{2}{*}{ MSCI world index } \\
\hline Coefficient & WTI & & \\
\hline \multirow[t]{2}{*}{$\varphi_{2} \mathrm{UPB}$} & $-0,0031 *$ & $\varphi_{2} \mathrm{DUBV}$ & $0,0042^{* *}$ \\
\hline & $(0,0018)$ & & $(0,0018)$ \\
\hline \multirow[t]{2}{*}{$\varphi_{3} \mathrm{DPB}$} & $-0,0104 * * *$ & $\varphi_{3}$ DDBVP & 0,0036 \\
\hline & $(0,0038)$ & & $(0,0022)$ \\
\hline \multirow[t]{2}{*}{$\varphi_{4} \mathrm{UBP} 1$} & $-0,0083^{* * *}$ & $\varphi_{4}$ DUBV1 & $0,0042^{* * *}$ \\
\hline & $(0,0022)$ & & $(0,0014)$ \\
\hline \multirow[t]{2}{*}{$\varphi_{5} \mathrm{DBP} 1$} & $-0,0024$ & & \\
\hline & $(0,0017)$ & & \\
\hline $\mathrm{R}^{2}$ & 0,9305 & & 0,9292 \\
\hline $\begin{array}{l}\text { Standard error of } \\
\text { regression }\end{array}$ & 0,0369 & & 0,0372 \\
\hline
\end{tabular}

Tests of contagion: Oil returns (WTI) and developed markets stock returns (MSCI World index) to emerging markets stock returns (MSCI emerging market index) 
Note: Table 2 reports coefficient estimates obtained from regressing the indicators of different periods of systematic shocks originated form the interaction between the WTI and MSCI world index to the proportion of idiosyncratic risk of the MSCI emerging market returns. In the case of indicators for shocks of oil the specification is $u_{s y s, e m e r_{t}}=\varphi_{0}+\varphi_{1} u_{s y s, \text { emer } r_{-1}}+\varphi_{2} U P B+\varphi_{3} D P B+\varphi_{4} U P B 1+\varphi_{5} D P B 1$ and in the case of developed markets (MSCI world index) is $u_{s y s, e m e r_{t}}=\varphi_{0}+\varphi_{1} u_{s y s, e m e r_{-1}}+\varphi_{2} D U B V+\varphi_{3} D D B P V+\varphi_{4} D U B V 1$ .Significant coefficients indicate contagion at the $* 90 \%, * * 95 \%, * * * 99 \%$ confidence level.

In Figure 3, we can observe the dynamic behavior of the systemic risk explained by the interaction of oil prices and developed markets stock markets. From Figure 3 we can observe that there are periods of increased systematic risk and other periods where risk from systematic factors tend to dampen.

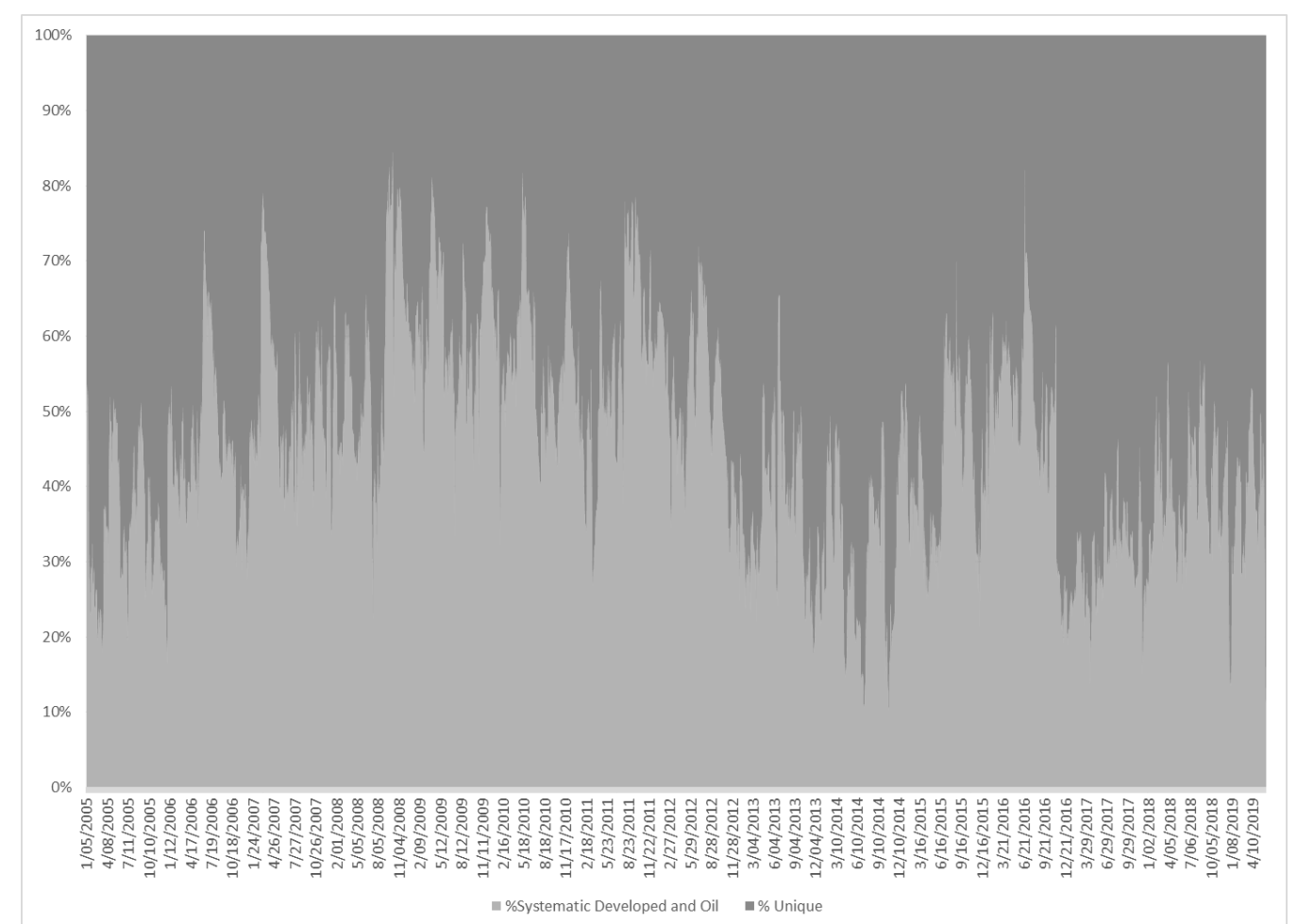

Figure 3. Conditional variance decomposition, MXLA emerging market index returns

Note: Figure graphs the proportion of conditional volatility of returns of the MXLA emerging market index due to systematic volatility to shocks in the price of oil and developed markets stock prices. The proportions are obtained using the using the estimates from equations (1) through (5).

From the results obtained in Table 2 and Figure 3 we can observe that in the first oil prices bullish period (UBP) the average systemic risk in emerging markets explained by these factors was $44.63 \%$. In the first bullish period for developed markets (DUBV) the average systemic risk explained by the factors was $43.12 \%$. In the first oil prices bearish period (DBP) the average systemic risk was $60.43 \%$ and in the case of the first developed markets bearish periods (DDBVP) the average systemic risk was 55.30\%. During the second oil prices bullish period (UPB1) the average systemic risk was $56.88 \%$ and for developed markets the average systemic risk for the second bullish period (DUBV1) was $47.39 \%$. For the last oil prices bearish period the average systemic risk was $43.22 \%$. The average systemic risk coming from the last part of the sample, namely the recovery periods, was $38.65 \%$ for oil (RPO) and $35.30 \%$ (RPV) for developed markets. 
From the contagion tests in Table 2 we can observe that the first bullish periods of oil and developed markets had a significant transmission effect to emerging markets stock prices. The coefficient sign for oil prices is negative and from developed markets is positive in all significant cases. This means that oil seems to reduce systemic risk in the case of emerging markets and developed markets tend to increase it. Of special interest is the fact that even with the interaction of oil it seems that emerging markets decoupled from shocks from developed markets form November 1, 2007 to March 9, 2009, which were the dates for the first bearish period from developed markets (DDBVP). In Table 3 we summarize the average results obtained for systemic risk attributable to shocks in the price of oil (WTI index), shocks in the prices of developed stock markets (MSCI world index) and their respective covariance which in turn give us the total systemic risk attributable to the interaction between the two explanatory factors

Table 3

Total systemic risk of the MSCI emerging market index attributable to shocks the WTI index (Oil) and the MCSI world index (Developed)

\begin{tabular}{|l|c|c|c|c|}
\hline Period & $\begin{array}{c}\text { Total systemic risk } \\
\text { attributable to MSCI } \\
\text { world index and the } \\
\text { WTI }\end{array}$ & $\begin{array}{c}\text { Contribution of } \\
\text { the MSCI world } \\
\text { index to systemic } \\
\text { risk }\end{array}$ & $\begin{array}{c}\text { Contribution of } \\
\text { the WTI to } \\
\text { systemic risk }\end{array}$ & $\begin{array}{c}\text { Contribution of the } \\
\text { covariance between } \\
\text { WTI, MSCI world } \\
\text { index to systemic } \\
\text { risk }\end{array}$ \\
\hline UBP & $\mathbf{4 4 , 6 3 \%}$ & $\mathbf{6 9 , 9 1 \%}$ & $\mathbf{2 4 , 1 3 \%}$ & $\mathbf{- 4 9 , 4 1 \%}$ \\
\hline DBP & $\mathbf{6 0 , 4 3 \%}$ & $\mathbf{7 1 , 8 3 \%}$ & $\mathbf{2 4 , 8 9 \%}$ & $\mathbf{- 5 0 , 2 0 \%}$ \\
\hline UBP1 & $\mathbf{5 6 , 8 8 \%}$ & $\mathbf{5 9 , 7 6 \%}$ & $\mathbf{1 3 , 2 5 \%}$ & $\mathbf{- 1 6 , 1 2 \%}$ \\
\hline DBP1 & $43,22 \%$ & $50,35 \%$ & $13,29 \%$ & $-20,42 \%$ \\
\hline RPO & $38,65 \%$ & $49,90 \%$ & $16,93 \%$ & $-28,18 \%$ \\
\hline DUBV & $\mathbf{4 3 , 1 2 \%}$ & $\mathbf{6 7 , 3 5 \%}$ & $24, \mathbf{3 1} \%$ & $-\mathbf{4 8 , 7 4 \%}$ \\
\hline DDBVP & $55,30 \%$ & $81,10 \%$ & $25,66 \%$ & $-51,46 \%$ \\
\hline DUBV1 & $\mathbf{4 7 , 3 9 \%}$ & $\mathbf{5 3 , 1 8 \%}$ & $\mathbf{1 4 , 4 7 \%}$ & $\mathbf{- 2 0 , 2 7 \%}$ \\
\hline RPV & $35,30 \%$ & $47,92 \%$ & $13,45 \%$ & $-26,07 \%$ \\
\hline
\end{tabular}

Note: The averages percentages of total systemic risk as a proportion of systemic risk and the respective contributions of each factor to systemic risk corrected by their covariance are obtained using the estimates from equations (1) through (5). The highlighted results denote the periods, which are statistically significant according to the contagion test of equation (6) according to the results in Table 2.

From Table 3 we can observe that for all periods under observation the covariance between developed markets and oil prices is negative. This negative covariance leads to a diversification effects, which in turns lowers the impact of developed market prices on the systemic risk of emerging markets. Of special interest are the periods where there is no evidence of contagion, which in our case is the first bearish period (DDBPV) for developed stock market prices that goes from November 1, 2007 to March 9, 2009 in line with previous findings of decoupling at the beginning of the GFC (Dooley \& Hutchison, 2009; Samarakoon, 2011). In the context of the contagion literature, this period is a very good example of high interdependence but no contagion as market volatility is set in a time-varying framework (Forbes \& Rigobon, 2002). In normal markets conditions, where is not possible to identify a clear trend (RPO) and (RPV) the proportion of the contribution of total systemic risk to emerging market variance is less than $40 \%$. Finally, when we compare the averages of systemic risk for the periods where there was evidence of contagion we find that total systemic risk is in average 123 basis points higher than in non-contagious periods. 
In order to test the robustness of the proposed model, we did a series of Breusch-Godfrey Lagrange multiplier tests for serial correlation for the residuals obtained from the specifications in equation (1) in order to check that indeed there were no autoregressive effects form the estimates of our ARMA models. In all three cases, we failed to reject the null hypothesis of no serial correlation in the estimates of our proposed ARMA models for the data analyzed:

Breusch-Godfrey Lagrange multiplier tests for serial correlation

\begin{tabular}{|c|c|c|c|}
\hline \multicolumn{4}{|c|}{$\begin{array}{l}\text { Null hypotheses: There is no serial correlation of the residuals obtained for the ARMA } \\
\text { specifications in equation (1). }\end{array}$} \\
\hline \multicolumn{4}{|c|}{$\begin{array}{l}\text { Alternative hypotheses: There is serial correlation of the residuals obtained for the ARMA } \\
\text { specifications in equation (1). }\end{array}$} \\
\hline & \multicolumn{3}{|c|}{ Residuals } \\
\hline Breusch-Godfrey LM test & $\varepsilon_{\text {emer }, t}$ & $\varepsilon_{o i l, t}$ & $\varepsilon_{\text {devel }, t}$ \\
\hline F-Statistic & 0.2483 & 0.5847 & 0.2513 \\
\hline $\mathrm{p}$-value & 0.9108 & 0.6737 & 0.9089 \\
\hline Chi-Statistic & 0.9946 & 2.3408 & 1.0065 \\
\hline p-value & 0.9106 & 0.6733 & 0.9088 \\
\hline
\end{tabular}

Note: This table summarizes the results obtained from running a Breusch-Godfrey LM test for serial correlation on the residual obtained from the ARMA specifications described in equation (1).

As we can observe from Table 4, in each of the proposed ARMA specification for the MSCI Emerging Market Index, WTI, and the MSCI World Market Index there is no evidence of serial correlation on the estimates of the proposed specifications.

\section{CONCLUSION}

In this paper, we studied the effect between two interacting explanatory factors and their effect of emerging market volatility. The explanatory factors were the change in prices form developed markets and oil prices. We found that the negative covariance between the WTI and the MSCI World Index helps to dampen the effect of systemic risk attributable to developed market shocks. Additionally, we found evidence that for the bearish period between November 1, 2007 and March 9, 2009, there was evidence of high interdependence but no contagion between the shocks originating from the interaction between the price of oil and developed markets to emerging markets. Finally, systemic risk emanating from bearish period in oil markets tends to be more contagious than bearish periods in developed markets.

\section{ACKNOWLEDGEMENT}

The authors are thankful to CESA Business School for covering the cost of the open source fee. 


\section{REFERENCES}

Arouri, M. E. H., Jouini, J., \& Nguyen, D. K. (2012). On the impacts of oil price fluctuations on European equity markets: Volatility spillover and hedging effectiveness. Energy Economics, 34(2), 611-617. doi:http://dx.doi.org/10.1016/j.eneco.2011.08.009

Basher, S. A., Haug, A. A., \& Sadorsky, P. (2018). The impact of oil-market shocks on stock returns in major oilexporting countries. Journal of International Money and Finance, 86, 264-280. doi:https://doi.org/10.1016/j.jimonfin.2018.05.003

Basher, S. A., \& Sadorsky, P. (2006). Oil price risk and emerging stock markets. Global Finance Journal, 17(2), $224-251$. doi: https://doi.org/10.1016/i.gfj.2006.04.001

Basher, S. A., \& Sadorsky, P. (2016). Hedging emerging market stock prices with oil, gold, VIX, and bonds: A comparison between DCC, ADCC and GO-GARCH. Energy Economics, 54, 235-247. doi:http://dx.doi.org/10.1016/j.eneco.2015.11.022

Byrne, J. P., Lorusso, M., \& Xu, B. (2019). Oil prices, fundamentals and expectations. Energy Economics, 79, 59-75. doi:https://doi.org/10.1016/j.eneco.2018.05.011

Cayon, E., \& Thorp, S. (2014). Financial autarchy as contagion prevention: the case of Colombian pension funds. Emerging Markets Finance and Trade, 50(sup3), 122-139. doi: 10.2753/REE1540-496X5003S307

Ding, H., Kim, H.-G., \& Park, S. Y. (2016). Crude oil and stock markets: Causal relationships in tails? Energy Economics, 59, 58-69. https://doi.org/10.1016/j.eneco.2016.07.013.

Dooley, M., \& Hutchison, M. (2009). Transmission of the U.S. subprime crisis to emerging markets: Evidence on the decoupling-recoupling hypothesis. Journal of International Money and Finance, 28(8), 1331-1349. doi:https://doi.org/10.1016/j.jimonfin.2009.08.004

Fang, S., \& Egan, P. (2018). Measuring contagion effects between crude oil and Chinese stock market sectors. The Quarterly Review of Economics and Finance, 68, 31-38. doi: https://doi.org/10.1016/i.qref.2017.11.010

Forbes, K. J., \& Rigobon, R. (2002). No contagion, only interdependence: measuring stock market comovements. Journal of Finance, 57(5), 2223-2261. doi: http://www.blackwellpublishing.com/journal.asp?ref=0022-1082

Guo, F., Chen, C. R., \& Huang, Y. S. (2011). Markets contagion during financial crisis: A regime-switching approach. International Review of Economics \& Finance, 20(1), 95-109. doi: https://doi.org/10.1016/j.iref.2010.07.009

Hassan, K., Hoque, A., \& Gasbarro, D. (2019). Separating BRIC using Islamic stocks and crude oil: dynamic conditional correlation and volatility spillover analysis. Energy Economics, 80, 950-969. doi:https://doi.org/10.1016/j.eneco.2019.02.016

Kayalar, D. E., Küçüközmen, C. C., \& Selcuk-Kestel, A. S. (2017). The impact of crude oil prices on financial market indicators: copula approach. Energy Economics, 61, 162-173. doi: http://dx.doi.org/10.1016/i.eneco.2016.11.016

Mensi, W., Hammoudeh, S., Shahzad, S. J. H., \& Shahbaz, M. (2017). Modeling systemic risk and dependence structure between oil and stock markets using a variational mode decomposition-based copula method. Journal of Banking \& Finance, 75, 258-279. doi: http://dx.doi.org/10.1016/j.jbankfin.2016.11.017

Raza, N., Jawad Hussain Shahzad, S., Tiwari, A. K., \& Shahbaz, M. (2016). Asymmetric impact of gold, oil prices and their volatilities on stock prices of emerging markets. Resources Policy, 49, $290-301$. doi:http://dx.doi.org/10.1016/j.resourpol.2016.06.011

Samarakoon, L. P. (2011). Stock market interdependence, contagion, and the U.S. financial crisis: The case of emerging and frontier markets. Journal of International Financial Markets, Institutions and Money, 21(5), 724-742. doi:https://doi.org/10.1016/j.intfin.2011.05.001

Wen, X., Wei, Y., \& Huang, D. (2012). Measuring contagion between energy market and stock market during financial crisis: A copula approach. Energy economics, 34(5), 1435-1446. doi: https://doi.org/10.1016/i.eneco.2012.06.021

Zhang, G., \& Liu, W. (2018). Analysis of the international propagation of contagion between oil and stock markets. Energy, 165, 469-486. doi: https://doi.org/10.1016/i.energy.2018.09.024 